\title{
Construction of mammalian expression vector of core gene of HCV of Pakistani isolate genotype la
}

\begin{abstract}
Background: Cell lines are a valuable tool to identify the HCV virus infection and propagation and by establishing cell lines expressing core protein we can explore the role of HCV core protein in development of HCC.

Results: The results indicate PCR amplification of 573bp product of core gene and sequencing confirmed the 1A genotype of $\mathrm{HCV}$ of Pakistani isolate. Then recombinant plasmid was digested with restriction enzymes (Hindi III and EcoR I) which gave fragments of $5.5 \mathrm{~kb}$ and $0.6 \mathrm{~kb}$ and It was a prove that our plasmid having a core gene. $21 \mathrm{KDa}$ core protein extracted from the transiently transfected Huh 7 cell line with recombinant mammalian vector of core gene was detected by using anti-core monoclonal antibody.
\end{abstract}

Conclusion: we successfully constructed a mammalian expression vector of core gene of Pakistani isolate of genotype 1A that was encoding 21KDa of core protein in Huh 7 cell line.

Keywords: Chronic hepatitis, HCV, vaccine, HCC, DNA, Hepatocellular carcinoma HCC
Volume 3 Issue 3 - 2016

\author{
Bushra Khubaib,' Muhammad Idrees,' Abrar \\ Hussain ${ }^{1,2}$ \\ 'National Centre of Excellence in Molecular Biology, University \\ of the Punjab, Pakistan \\ 2Department of Microbiology, Baluchistan University of \\ Information Technology, Engineering and Management Sciences, \\ Quetta
}

Correspondence: Abrar Hussain, Department of Microbiology, Balochistan University of Information Technology, Engineering and Management Sciences, Airport Road, Baleli, Quetta, Pakistan, Tel 92 (8I) 28804I0, 92 (8I) 288I036, Email abrarbangash176@hotmail.com

Received: April 03, 2016 | Published: April 19, 2016
Abbreviations: HCV, Hepatitis C Virus; ABI, Applied Biosystem Inc; RT-PCR, Reverse Transcriptase Polymerase Chain Reaction; cDNA, Complimentary DNA, MMLV, Moloney Murine Leukemia Virus; HCC; Hepatocellular Carcinoma; SST, Serum Separation Tubes

\section{Background}

Chronic hepatitis is mostly caused by Hepatitis $\mathrm{C}$ virus and it is reported that 170 million people worldwide are infected with this virus $^{1}$ that frequently leads to hepatocellular carcinoma in $10 \%$ to $80 \%$ patients in different populations. In Pakistan, HCC is a leading cause of death and accounts for $60 \%-90 \%$ of all primary liver malignancies. ${ }^{2}$

In 1989, HCV was identified, a positive sense, single stranded RNA enveloped virus in length of 9600 nucleotides that encodes a polyprotein with 3 structural (Core, E1, E2) and 7 nonstructural (p7, NS2, NS3, NS4A-B, and NS5A-B) proteins. ${ }^{3-4}$

Molecular events that develop HCC during HCV infection are feebly identified. In this regard, HCV core protein takes an important part in the development of Hepatocellular carcinoma and steatosis in transgenic mice. ${ }^{5-6}$ Core gene is highly conserved region in different genotypes of $\mathrm{HCV}$ so it is an ideal candidate for DNA vaccine development. ${ }^{7}$ Protein encoded by it is extremely basic in nature that forms the nucleocapsid of virus. At its $\mathrm{N}$ terminal Core protein of $\mathrm{HCV}$ is rich in arginine and lysine amino acids and it binds with RNA in order to form an envelope of $\mathrm{HCV}{ }^{8}$

Although main function of core protein is in genome packaging, but its sub cellular localization reveals that it modulates numerous cellular processes. ${ }^{9}$ Localization of core protein into mitochondria indicates that it modulate apoptosis and lipid transfer. ${ }^{10}$ In cytoplasm, it accumulated on lipid droplets and co localized on apolipoprotein AII shows its dealing with cellular lipid metabolism. ${ }^{11}$ When hydrophobic part at C-terminal of core protein is deleted, it translocated in nucleus ${ }^{12}$ and interacted with several cellular proteins, like cytopalsmic tail of lymphotoxin- $\beta$ receptor, ${ }^{13}$ retinoid X receptor- $\alpha$, type 1 TNF- $\alpha$ receptor and nuclear ribonucleo-protein $\mathrm{K} .{ }^{14}$
$\mathrm{HCV}$ core protein is multifunctional protein it modulate multiple intracellular signaling pathways like proliferation of cell, apoptosis, cell cycle, various oncogenes and growth factors and stimulate humoral and cellular immune system. ${ }^{15}$ It is involved in plasmacytoid dendritic cells apoptosis and inhibition of IFN- $\alpha$ production, ${ }^{16}$ suppress the p53 transcription, ${ }^{17}$ repress the phosphorylation and DNA binding property of stat $3,{ }^{18}$ and suppresses cell proliferation and apoptosis by preventing the phosphorylation of MAPKs and stimuating the transcriptors NF-kappaB and AP-1, thus endorse the HCV persistent infection leads to chronic hepatitis $\mathrm{C}$ disease and hepatocellular carcinoma. ${ }^{19}$

The aim of the study was to construct a recombinant mammalian expressing vector of core gene of Pakistani isolate of HCV genotype $1 \mathrm{~A}$ and to establish an experimental model for exploring the role of $\mathrm{HCV}$ core protein in development of HCC.

\section{Material and methods}

\section{Sample collection and RNA isolation}

Patients era infected with Hepatitis C virus, genotype 1A, were obtained from Molecular Diagnostics lab, CEMB, University of the Punjab Lahore by using BD Vacutainer collection tubes (Becton Dickenson). For isolation of serum, serum separation tubes (SST) were used. The serum was recovered after centrifugation at $2000 \mathrm{~g}$ for 10 minutes. RNA was isolated from $100 \mu$ l of serum, using commercially available Gentra RNA isolation kit (Puregene, Minneapolis, MN 55441 USA), according to the kit protocol with little modification.

\section{cDNA synthesis and PCR amplification}

Reverse transcription (RT) was performed by incubating the $10 \mu \mathrm{L}$ of RNA used as template in a $10-\mu \mathrm{L}$ reaction mixture having 10 picomole (pmol) of core specific antisense primer COAS (Table 1), 100 units of MMLV reverse transcriptase (invirtogen), 10 units Ribolock RNase Inhibitor (Fermentas), 1X First Strand Buffer (invitrogen), and $10 \mathrm{mM}$ deoxynucleotide triphosphates (dNTPs) at $37^{\circ} \mathrm{C}$ for 50 minutes, $42^{\circ} \mathrm{C}$ for 10 minutes, $95^{\circ} \mathrm{C}$ for 3 minutes and $20^{\circ} \mathrm{C}$ 
for 2 minutes. PCR Amplification of core region of HCV was done by using $4 \mu 1$ of synthesized cDNA as template with outer forward COS and reverse COAS (Table 1) primers. Then $2 \mu 1$ of first round product was taken as template and re- amplified by performing nested PCR with internal forward CIS (Table 1) and reverse CIAS primers. The amplified PCR product was run on $2 \%$ agarose gel having ethidium bromide and visualized under a Ultra Violet transilluminator. The amplified product of $573 \mathrm{bp}$ was purified by using Bead DNA Gel Extraction Kit (Fermentas CAT\# K0513).

Table I Gene specific primer sequence of HCV core region

\begin{tabular}{lll}
\hline Primer & & Sequence \\
\hline Outer sense & COS & 5' GTAGACCGTGCACCATGAGC-3' \\
Outer Antisense & COAS & 5' ATGGTAAAGCCCCGAGGAAT -3' \\
Inner Sense & CIS & 5'AGGACCCCTGCTCGIGTTAC-3 \\
Inner Antisense & CIAS & 5'AGATGATGGGATG-GGIUTAC-3' \\
Restriction Sense & RCIS & 5'-GCAAGCTTGCCATGGCCATGAGCA \\
& & CGAATCCTAAACCTC-3 \\
Restriction Antisense & RCIAS & 5'-GCAAGCTTGCCATGGCCATGAGCA \\
& & CGAATCCTAAACCTC-3 \\
\hline
\end{tabular}

*Primers sets were synthesis by using reference sequence of genotype IA Genbank accession number AF0096096.I.

\section{Sequencing PCR}

Amplification of core gene of genotype 1A was confirmed by sequencing that performed by using ABI PRISM 3100 Genetic Analyzer (Applied Biosystem Inc., Foster City, CA, USA) in both directions.

\section{TA cloning}

Purified core gene ligated into TA vector by using TA cloning kit (Cat\# K2020-20, Invitrogen) and the manufacturer's protocol was followed. The ligated product was transformed into E.coli strain TOP10F and competent cells that have taken up recombinant plasmid are then selected onto a Luria-Bertani agar plate having $100 \mu \mathrm{g} / \mathrm{ml}$ of ampicillin and $12.5 \mu \mathrm{g} / \mathrm{ml}$ of tetracyclin. Colony PCR was performed with two sets of primers (gene specific primers CIS, CIAS and T/A vector specific primers). Then recombinant plasmid, named as PAK$\mathrm{C} 1 \mathrm{~A}$, was digested with restriction enzyme ECOR I and digested DNA was checked on $1 \%$ agarose stained with ethidium bromide under U.V illuminator.

\section{Construction of expression vector}

The PAK-C1A plasmid containing core region was used as template for PCR amplification of core region. A set of restriction primers RCIS and RCIAS (Table 1), having restriction sites for enzymes HindIII and EcoR 1 in the inner set of sense and antisense primers at 5 site respectively, was used for PCR amplification. The amplified product was digested with enzymes and recombined into pcDNA3.1 (+) mammalian expression vector (Invitrogen). The recombinant was transformed into E.coli strain TOP10F and positive colonies were cultured in Luria-Bertani medium (LB media) having $100 \mu \mathrm{g} /$ $\mathrm{ml}$ ampicillin and $12.5 \mu \mathrm{g} / \mathrm{ml}$ of tetracyclin. In order to confirm the fragment insertion into vector Colony PCR was performed with two sets of primers, gene specific (CIS \& CIAS) and vector specific (T7 \& $\mathrm{BGH}$ ) primers. 1.5\% Agarose gel electrophoresis was run to visualize PCR product. The recombinant mammalian expression vector, named as pcDNA-PKcore, was extracted using GeneJet Plasmid Miniprep Kit (Fermantas CAT \# K0503) and further confirmation was done by restriction analysis. The proper orientation core gene of HCV encoding protein was confirmed by sequence analysis.

\section{Huh 7 cell line and transient transfection}

Huh-7 human liver hepatoma cell lines (American type cell culture) were grown in Dulbeccos modified Eagles medium (ICN technologies USA) have $100 \mathrm{ug} / \mathrm{ml}$ streptomycin and $100 \mathrm{U} / \mathrm{ml}$ penicillin and $10 \%$ Fetal bovine serum (FBS) (Gibco life science technologies USA). Three days before transfection cells were seeded onto $60 \mathrm{~mm}$ petri plate and when cells became $70-80 \%$ confluent then transient transfection was performed using Lipofectamine-plus ${ }^{2000}$ reagent (Invitrogen), following the manufacturer's protocol.

\section{Reverse transcription (RT) PCR analysis}

To characterize the core producing cell, we have screened the expression profiles of cell line by RT-PCR. After 24 hours of Transfection, total cellular RNA was extracted using RNA Isolation Kit (Gentra biotronics USA) and rehydrated into $20 \mu \mathrm{l}$ of RNA hydration solution for 30 minutes at $4^{\circ} \mathrm{C}$. Then $10 \mu \mathrm{l}$ of this hydrated RNA was used for RT-PCR using antisense primer CIAS. The product of RT-PCR was subjected to PCR amplification using primers CIS and CIAS.

\section{Western blot analysis}

Protein was extracted from Huh 7 cells transiently transfected with recombinant and control plasmid. Media was removed from the transfected plates and cells were trypsinized for 2-3 mins to detach the cells from the surface. Then $1000 \mu$ of DMEM media was added in the plate and mixed well to resuspend the cells in the media. Cells were shifted into a new sterile eppendorf and spinned for 3 minutes at $8000 \mathrm{rpm}$. Cells were washed with $500 \mu \mathrm{l}$ of $1 \mathrm{X}$ PBS, resuspending the cells and centrifuged for 3 minutes at $8000 \mathrm{rpm}$. Supernatant was discarded and $60 \mu \mathrm{l}$ of lysis solution, containing $150 \mathrm{mM} \mathrm{NaCl}, 5 \mathrm{mM}$ EDTA, $1 \%$ triton $100,0.01 \mathrm{M}$ tris $\mathrm{HCl}(\mathrm{pH} 7.4), 0.1 \mathrm{mM}$ PMSF and Proteinase inhibitor cocktail, was added to the pellet and kept on ice for 10 minutes. Then centrifuged $(13000 \mathrm{rpm})$ at $4^{\circ} \mathrm{C}$ for $10 \mathrm{~min}$ and supernatant was shifted to a new sterile eppendorf. Mixed with 45 $\mu \mathrm{l}$ of $2 \mathrm{X}$ sample loading dye and heat shocked in boiling water for 10 minutes and immediately transferred on ice for 5 to 10 minutes. Then SDS-PAGE was performed and protein was transfer onto nitrocellulose membrane. The membrane was incubated into 5\% skim milk (blocking solution), then overnight incubated at $4^{\circ} \mathrm{C}$ into primary monoclonal anti mouse antibody (Santa Cruz Biotechnology). Then washed with 1x PBST and incubated in secondary antibody, conjugated with alkaline phosphatase (AP), for 1 hour at $37^{\circ} \mathrm{C}$. Then $\mathrm{HCV}$ core protein was detected by chemiluminescence using NBTBICP tablets (Sigma).

\section{Results}

\section{PCR amplification}

The cDNA was synthesized using gene specific outer anti sense primer COAS $(25 \mathrm{pm})$. Then nested PCR was performed using two sets of primer outer set COAS and COS and inner set CIAS and CIS of primers (Figure 1). The PCR products obtained after amplification were run on the $1.5 \%$ agarose gel and stained with ethidium bromide $(0.5 \mathrm{mg} / \mathrm{ml})$ and were visualized by UV transillumination. The $573-$ bp fragments produced by PCR were identified by comparison with a molecular mass marker (Figure 2).

\section{Sequencing PCR}

Identification of amplified product was confirmed by sequencing PCR. Sequences of the core gene of HCV genotype 1A of Pakistani Isolate were searched for homology with other sequences in GeneBank 
and submitted to NCBI Genbank data base. The assigned Accession numbers for the local core gene sequence is GQ451336.

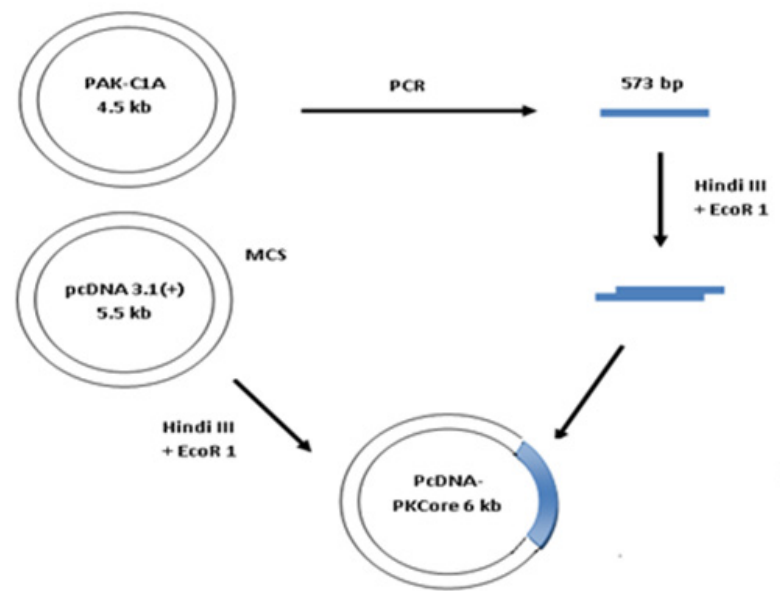

Figure I Construction of mammalian expression vector designated as pcDNA-PKcore.

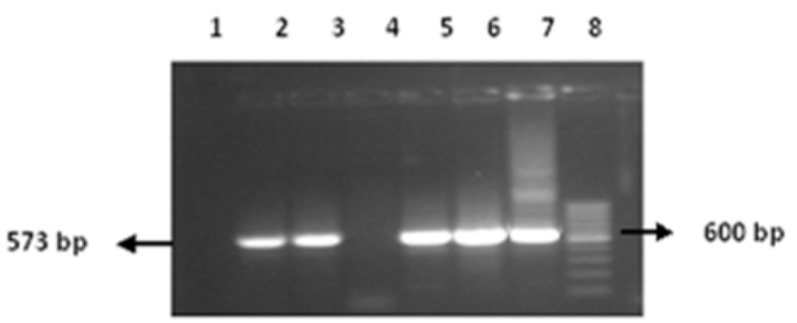

Figure 2 PCR Amplification of HCV core gene. Lane 2-3 \& 5-7: bands of core gene, Lane: I\&4 negative control.

Lane 8: 50 bp marker.

\section{TA Cloning Of HCV Core Gene PCR Results}

The freshly eluted PCR product was ligated in the TA vector. The ligation reaction was used to transform into E.Coli strain TOP10F Competent cells that have taken up plasmid were selected by spreading the culture onto a Luria-Bertani (LB) agar plate containing $100 \mu \mathrm{g} / \mathrm{ml}$ of ampicillin and $12.4 \mu \mathrm{g} / \mathrm{ml}$ of tetracyclin. Colonies were selected by incubating the plate overnight at $37^{\circ} \mathrm{C}$. To identify bacteria harboring cloned core gene, individual colonies were used to directly inoculate for colony PCR reactions using gene specific primers (Figure 3a). The results of vector specific primers counter proofs the presence of genes of interest in the TA vector as these primers originates from the outer regions of the cloned gene and PCR product of vector specific primer approximately $769 \mathrm{bp}$ (Figure $3 \mathrm{~b}$ ). The resulting colonies were further analyzed by restriction digestion (Figure $3 \mathrm{c}$ ) and DNA sequencing which shows homology with previously submitted sequence.

\section{Cloning of HCV Core Gene in mammalian expression Vector Pcdna3.I}

In order to characterize the role of core gene in disease progression we cloned the amplified PCR product in mammalian expression vector pc DNA 3.1(+). The vector has a CMV promoter which represents an effective mean to transduce eukaryotic cells for transient and stable expression studies (Table 1). The amplified sequence encoding core gene was digested, purified and cloned in expression vector between Hindi III and EcoR I sites. In order to clone CORE gene into pcDNA it is nessecary to amplified the core gene by using restriction primers RCIAS and RCIS and then ligated into pcDNA. Positive clones were used for amplification of the cloned core genes by using gene specific (CIS \& CIAS) and vector specific primers (T7 and BGH) (Figure 4A). The results of vector specific primers counter proofs the presence of genes of interest in the expression vector as these primers originates from the outer regions of the cloned genes. Then recombinant plasmid was digested with restriction enzymes (Hindi III and EcoR I) which gave fragments of $5.5 \mathrm{~kb}$ and $0.6 \mathrm{~kb}$ (Figure 4B). It was a prove that our plasmid having a core gene. The presence of ATG, a start codon required for initiation of translation of protein, was confirmed by sequence of the pcDNA-PKCore plasmid.

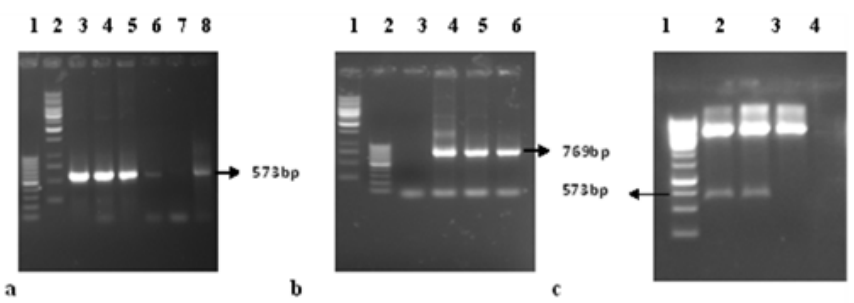

Figure 3 A. Colony PCR for screening of positive clones: Lane I, I00bp marker. Lane 2, I kb marker. Lane 3-8, Core Encoding clones with gene specific primers. b. Colony PCR for screening of positive clones: Lane I, I kp marker. Lane 2, I00bp marker. Lane 3-6, Core Encoding clones with vector specific primers.c. Gel picture for restriction digestion of core gene coding TA vector: Lane I, I kp marker. Lane 2 and 3, show digested TA vector with required size of gene. Lane 4, shows digested TA vector but do not have gene.

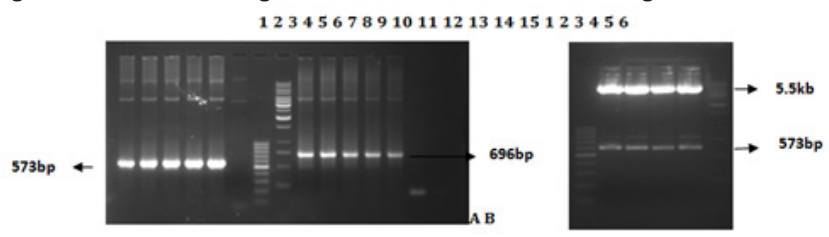

Figure 4A A.Colony PCR for screening of positive clones: Lane I-6, Core Encoding clones with gene specific primers, Lane 7, $100 \mathrm{bp}$ ladder. Lane 8, I kb ladder. Lane 9-14, Core Encoding clones with vector specific primers. Lane I5, -ve Control. B. Gel picture for restriction digestion of core gene coding pcDNA-PKCore vector: Lane I, I00bp marker. Lane 2 to 5, show digested vector with required size of gene. Lane 6 , I kp marker.

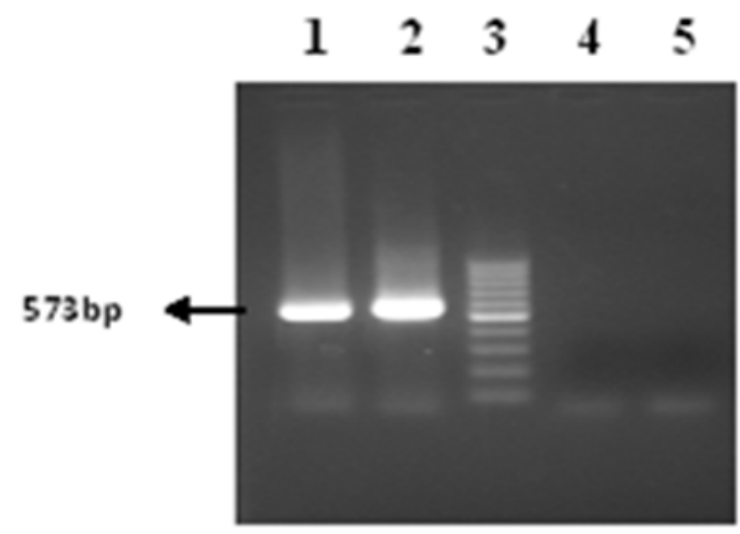

Figure 4B RT-PCR was done to characterize the core producing cell. Lane I-2, RT-PCR transfected cells, lane 3 lo0bp marker \& lane 4, RT-PCR of transfected cells with control plasmid. Lane 5, RT-PCR of untransfected Huh 7 cell line as a negative control.

\section{Expression of core protein in transfected Huh 7 CELLS}

Huh 7 cells were transiently transfected with core expressing vector pcDNA-PKCore and protein extraction was done from cells after 48 and 72 hours. Control plasmid pcDNA $3.1(+)$ was also used 
to transfect the cells. Expression of HCV core proteins coded by expression vector was checked with protein extracts of transfected Huh-7 cells using mouse monoclonal sera against core (Santa Cruz Biotechnologies Inc. USA). The Western blot analysis identified specific bands of the expected electrophoretic mobility for core having molecular weight of $21 \mathrm{kDa}$ (Figure 5). These results shows that Huh 7 cells transfected with the pcDNA-PKCore could express HCV core protein.

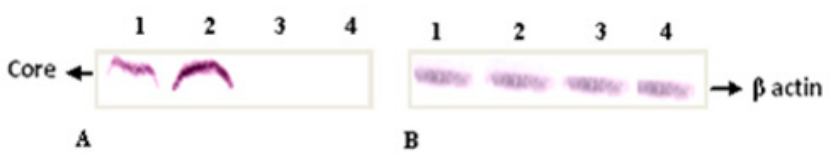

Figure $5 \mathrm{~A}$. Western blot of core protein of HCV, detected with the anti-core antibodies. Lane I: core protein at $48 \mathrm{hr}$ post transfection, lane 2: core protein at $72 \mathrm{hr}$ post transfection and Lane 3: protein extracted from transfected cells with control plasmid, lane 4: negative control, protein extracted from untransfected huh 7 cells. B. western blot of $\beta$ actin, protein expression of a house keeping gene, was used as a control. Lane I: at $48 \mathrm{hr}$ post transfection, lane 2:at 72 hr post transfection and Lane 3:protein extracted from transfected cells with control plasmid, lane 4: negative control, protein extracted from untransfected huh 7 cells.

\section{Discussion}

$\mathrm{HCV}$ core protein acts as multifunctional protein and at molecular level, it constitutes the virus capsid, ${ }^{20,21}$ associates in $\mathrm{HCV}$ pathogenesis, ${ }^{22}$ involves in hepatocellular fibrosis, steatosis and carcinogenesis, ${ }^{23}$ shows significance in $\mathrm{HCV}$ diagnosis ${ }^{24}$ and as most conserve region of $\mathrm{HCV}$ in all genotypes it is an important candidate gene for DNA based vaccine development against $\mathrm{HCV}$ infection ${ }^{25}$ all these functions indicates its critical role to induce $\mathrm{HCV}$ viral hepatitis that develop into carcinoma.

Although hepatitis $\mathrm{C}$ virus cause the persistent infection but to sustain the viral replication in vitro system of cell culture is very difficult and lack of small animal model is the major hinder to explore the HCV replication and propagation. Other than human the only hosts of $\mathrm{HCV}$, are chimpanzees ${ }^{26}$ and small animal model, trimera mice. ${ }^{27}$ In this regard, cell lines are a valuable tool to identify the virus infection and propagation..$^{28-29}$

In this study we constructed a recombinant mammalian expression vector of $\mathrm{HCV}$ core gene by using molecular cloning techniques that efficiently expressing core protein in Huh cell line. HCV RNA of Pakistani isolate genotype 1A was extracted from serum of HCV infected chronic patient and core specific primers was used for nested PCR amplification of core. Then amplified product was ligated into T/A cloning vector, PAK-C1A, which further used for amplification of core gene with restriction primers. Amplified product after restriction digestion was ligated into pcDNA 3.1(+) and recombinant plasmid pcDNA-PKCore was obtained, restriction analysis and sequencing PCR was used to identify newly constructed plasmid. Then it was used to transfect the $70-80 \%$ confluent Huh 7 cells with lipofectamine reagent. RNA expression of core gene in transfected cells was confirmed by performing RT-PCR after 24 hours of transfection and western blotting confirmed the successful expression of core protein after 48 hours and 72 hours transiently transfected cells. Our results show the successful cloning and expression of mammalian expression vector of core gene of $\mathrm{HCV}$.

\section{Conclusion}

We conclude that newly constructed mammalian expression vector, pcDNA-PKCore, is efficiently transcribing RNA and encoding core protein in Huh cell line. That, pcDNA-PKCore, can be used for establishing the stable cell lines expressing $\mathrm{HCV}$ core protein which may be helpful to explore the molecular events that are affected by core protein in cells.

\section{Acknowledgments}

None.

\section{Conflicts of interest}

None.

\section{References}

1. Global surveillance and control of hepatitis C. Report of a WHO Consultation organized in collaboration with the Viral Hepatitis Prevention Board, Antwerp, Belgium. J Viral Hepat. 1999;6(1):35- 47.

2. Idrees M, Rafique $\mathrm{S}$, Rehman $\mathrm{A}$, et al. Hepatitis $\mathrm{C}$ virus genotype $3 \mathrm{a}$ infection and hepatocellular carcinoma: Pakistan experience. World $J$ Gastroenterol. 2009;15(40):5080-5085.

3. Choo QL, Kuo G, Weiner AJ, et al. Isolation of a cDNA clone derived from a blood-borne non-A, non- B viral hepatitis genome. Science. 1989;244(4902):359-362.

4. Jhaveri R, Kundu P, Shapiro AM, et al. Effect of Heptitis C Virus Core Protein on Cellular Gene Expression: Specific Inhibition of Cyclooxygenase 2. J Infect Dis. 2005;191(9):1498-1506.

5. Moriya K, Fujie H, Shintani Y, et al. The core protein of hepatitis C virus induces hepatocellular carcinoma in transgenic mice. Nat Med. 1998;4(9):1065-1067.

6. Moriya $\mathrm{K}$, Yotsuyanagi $\mathrm{H}$, Shintani $\mathrm{Y}$, et al. Hepatitis $\mathrm{C}$ virus core protein induces hepatic steatosis in transgenic mice. J Gen Virol. 1997;78(pt 7):1527-1531

7. Lagging LM, Meyer $\mathrm{K}$, Hoft $\mathrm{D}$, et al. Immune Responses to Plasmid DNA Encoding the Hepatitis C Virus Core Protein. $J$ Virol. 1995;69(9):5859-5863.

8. Santolini F, Migliaccio G, and Monica NL. Biosynthesis and Biochemical Properties of the Hepatitis C Virus Core Protein. $J$ Virol. 1994;68(6):3631-3641.

9. Majeau N, Gagne V, Boivin A, et al. The N-terminal half of the core protein of hepatitis $\mathrm{C}$ virus is sufficient for nucleocapsid formation. $J$ Gen Virol. 2004;85(Pt 4):971-981.

10. Schwer B, Ren S, Pietschmann T, et al. Targeting of Hepatitis C Virus Core Protein to Mitochondria through a Novel C-Terminal Localization Motif. J Virol. 2004;78(15):7958-7968.

11. Barba G, Harper F, Harada T, et al. Hepatitis C virus core protein shows a cytoplasmic localization and associates to cellular lipid storage droplets. Proc Natl Acad Sci. 1997;94(4):1200-1205.

12. Suzuki R, Matsuura Y, Suzuki T, et al. Nuclear localization of the truncated hepatitis $\mathrm{C}$ virus core protein with its hydrophobic $\mathrm{C}$ terminus deleted. J Gen Virol. 1995;76(Pt 1):53-61.

13. Matsumoto M, Hsieh T, Zhu N, et al. Hepatitis C Virus Core Protein Interacts with the Cytoplasmic Tail of Lymphotoxin-b Receptor. $J$ Virol. 1997;71(2):1301-1309.

14. Alisi A, Giambartolomei S, Cupelli F, et al. Physical and functional interaction between $\mathrm{HCV}$ core protein and the different p73 isoforms. Oncogene. 2003;22(17):2573-2580.

15. Fukutomi T, Zhou Y, Kawai S, et al. Hepatitis C Virus Core Protein Stimulates Hepatocyte Growth: Correlation With Upregulation of wnt-1 Expression. Hepatology. 2005;41(5):1096-1105. 
16. Dolganiuc A, Chang S, Kodys K, et al. Hepatitis C Virus (HCV) Core Protein-Induced, Monocyte-Mediated Mechanisms of Reduced IFN- $\alpha$ and Plasmacytoid Dendritic Cell Loss in Chronic HCV Infection. $J$ Immunol. 2006;77(10):6758-6768.

17. Ray RB, Steele R, Meyer K, et al. Transcriptional repression of p53 promoter by hepatitis $\mathrm{C}$ virus core protein. J Biol Chem. 1997;272(17):10983-10986.

18. Feng DY, Li B, Zheng H, et al. Regulation of hepatitis $\mathrm{C}$ virus core protein on the activity of signal transducers and activators of transcription 3. Zhong Nan Da Xue Xue Bao Yi Xue Ban. 2005;30(6):631-635.

19. Li B, Feng DY, Cheng RX, et al. The effects of hepatitis C virus core protein on biological behaviors of human hepatocytes. Zhonghua Yi Xue Za Zhi. 2005;85(18):1243-1248.

20. Matsumoto M, Hwang SB, Jeng KS, et al. Homotypic interaction and multimerization of hepatitis-C virus core protein. Virology. 1996;218(1):43-51.

21. Nolandt O, Kern V, Muller H, et al. Analysis of hepatitis-C virus core protein interaction domains. J Gen Virol. 199778(Pt 6):1331-1340.

22. Irshad M, Dhar I. Hepatitis C Virus Core Protein: An Update on Its Molecular Biology, Cellular Functions and Clinical Implications. Med Princ Pract. 2006;15(6):405-416.
23. Okabe H, Satoh S, Kato T, et al. Genome-wide analysis of gene expression in human hepatocellular carcinomas using cDNA microarray: identification of genes involved in viral carcinogenesis and tumor progression. Cancer Res. 2001;61(5):2129-2137.

24. Akbar H, Idrees M, Manzoor S, et al. Hepatitis $\mathrm{C}$ virus infection: A review of the current and future aspects and concerns in Pakistan. Journal of General and Molecular Virology. 2009;1(2):12-18.

25. Lagging LM, Meyer $\mathrm{K}$, Hoft $\mathrm{D}$, et al. Immune Responses to Plasmid DNA Encoding the Hepatitis C Virus Core Protein. J Virol. 1995;69(9):5859-5863.

26. Yanagi M, Purcell RH, Emerson SU, et al. Transcripts from a single full-length cDNA clone of hepatitis $\mathrm{C}$ virus are infectious when directly transfected into the liver of a chimpanzee. Proc Natl Acad Sci USA. 1997;94(16):8738-8743.

27. Ilan E, Arazi J, Nussbaum O, et al. The hepatitis C virus (HCV)-Trimera mouse: a model for evaluation of agents against HCV. $J$ Infect Dis. 2002;185(2):153-161.

28. Lohmann V, Korner F, Koch J, et al. Replication of sub genomic hepatitis C virus RNAs in a hepatoma cell line. Science. 1999;285(5424):110-113.

29. Moreira JP, Malta FM, Diniz MA, et al. Interferon lambda and hepatitis $\mathrm{C}$ virus core protein polymorphisms associated with liver cancer. Virol. 2016;493:136-141. 